\title{
Evidence for Carrier-mediated Chloride/Bicarbonate Exchange in Canalicular Rat Liver Plasma Membrane Vesicles
}

Peter J. Meier, Roy Knickelbein, Richard H. Moseley, J. W. Dobbins, and James L. Boyer

Liver Study Unit, Department of Medicine, Yale University School of Medicine, New Haven, Connecticut 06510

\begin{abstract}
To determine whether anion exchangers might play a role in hepatic bile formation, we looked for the presence of $\mathrm{Cl}^{-}: \mathrm{OH}^{-}$ and $\mathrm{Cl}^{-}: \mathrm{HCO}_{3}^{-}$exchange in highly purified canalicular (c) and basolateral (bl) rat liver plasma membrane (LPM) vesicles. In cLPM vesicles, a pH gradient (7.7 in/6.0 out) stimulated ${ }^{36} \mathrm{Cl}^{-}$ uptake twofold above values obtained during $\mathrm{pH}$-equilibrated conditions $(7.7$ in $=$ out $)$. When $50 \mathrm{mM} \mathrm{HCO}_{3}^{-}$was also present inside the vesicles, the same $\mathrm{pH}$ gradient $(7.7 \mathrm{in} / 6.0$ out) resulted in $\mathrm{Cl}^{-}$uptake to levels fourfold above $\mathrm{pH}$ - and $\mathrm{HCO}_{3}^{-}$-equilibrated controls and two- to threefold above $\mathrm{Cl}^{-}$ equilibrium (overshoot). Initial rates of both $\mathrm{pH}$ and $\mathrm{HCO}_{3}^{-}$ gradient-stimulated $\mathrm{Cl}^{-}$uptake were completely inhibited by 4,4'-diisothiocyano-2,2'-disulfonic acid stilbene (DIDS). A valinomycin-induced $\mathrm{K}^{+}$diffusion potential (inside positive) also stimulated $\mathrm{Cl}^{-}$uptake in cLPM, but this conductive $\mathrm{Cl}^{-}$ pathway was insensitive to DIDS. The DIDS-sensitive, pH and $\mathrm{HCO}_{3}^{-}$gradient-stimulated $\mathrm{Cl}^{-}$uptake demonstrated: (a) saturation with $\mathrm{Cl}^{-}\left(K_{\mathrm{m}} \sim 6.3 \mathrm{mM} ; V_{\max } \sim 51\right.$ $\left.\mathrm{nmol} \cdot \mathrm{mg}^{-1} \cdot \mathrm{min}^{-1}\right)$; (b) partial inhibition by bumetanide $(26 \%)$, furosemide (33\%), probenecid (37\%), and 4-acetamido-4'-isothiocyano-2,2'-disulfonic acid stilbene (49\%); (c) cis-inhibition by chloride and nitrate but not by sulfate and various organic anions, and $(d)$ independence from the membrane potential. These data demonstrate the presence of an electroneutral $\mathrm{Cl}^{-}$: $\mathrm{OH}^{-}$and $\mathrm{Cl}^{-}: \mathrm{HCO}_{3}^{-}$exchanger in rat liver canalicular membranes that favors $\mathrm{Cl}^{-}: \mathrm{HCO}_{3}^{-}$exchange. In contrast, no evidence was found for the presence of a $\mathrm{Cl}^{-}: \mathrm{HCO}_{3}^{-}\left(\mathrm{OH}^{-}\right)$exchange system in blLPM vesicles. Furthermore, neither blLPM nor cLPM vesicles exhibited $\mathrm{Na}^{+}$-stimulatable $\mathrm{Cl}^{-}$uptake, indicating the absence of a $\mathrm{NaCl}$ co-transport system in either LPM subfraction. These findings are consistent with a functional role for a $\mathrm{Cl}^{-}: \mathrm{HCO}_{3}^{-}\left(\mathrm{OH}^{-}\right)$exchanger in canalicular bile formation.
\end{abstract}

\section{Introduction}

Bile formation is a major function of the liver. According to current views canalicular bile flow is mainly an osmotic process in which water and electrolytes diffuse either from the cell or paracellularly from plasma into bile canaliculi along osmotic

Dr. P. J. Meier is supported by a postdoctoral fellowship from the Swiss National Science Foundation and the Swiss Foundation for Experimental Medicine and Biology. Dr. Meier's present address is Division of Clinical Pharmacology, Department of Internal Medicine, University Hospital, 8091 Zurich, Switzerland. Address reprint requests to Dr. Boyer.

Received for publication 6 April 1984 and in revised form 30 October 1984.

J. Clin. Invest.

(c) The American Society for Clinical Investigation, Inc.

0021-9738/85/04/1256/08 $\$ 1.00$

Volume 75, April 1985, 1256-1263 gradients resulting from the active hepatocellular secretion of inorganic and organic solutes into the canalicular lumen (for reviews, see references 1-6). Conceptually, canalicular bile formation is generally divided into bile acid-dependent bile flow (BADF) ${ }^{1}$ and bile acid-independent bile flow (BAIF) components. Although these two fractions of canalicular bile flow may not be totally independent from each other, bile acids represent the most potent endogenous stimulants of bile secretion. Recent studies with plasma membrane vesicles selectively isolated from the basolateral (i.e., sinusoidal and lateral) and canalicular pole of rat hepatocytes have indicated that transhepatocyte excretion of taurocholate, the most abundant conjugated bile acid in the rat, is a secondary active transport process driven by the electrochemical potential difference for $\mathrm{Na}^{+}$across the basolateral membranes $\left(\mathrm{Na}^{+}\right.$-taurocholate co-transport) and by the electrical potential difference across the bile canalicular membranes (facilitated diffusion; 7, 8). In contrast, the mechanisms responsible for BAIF are more poorly understood. Indirect studies in the isolated perfused rat liver have suggested that active canalicular secretion of anions such as chloride (5), bicarbonate (9-11), and/or acidic oligopeptides and amino acid conjugates $(5,12)$ could account for the formation of BAIF.

In the present study we tested the hypothesis that anion exchange mechanisms (13-15) may play a primary role in transhepatocytic excretion of anions. Specifically we investigated mechanisms of chloride $\left(\mathrm{Cl}^{-}\right)$and bicarbonate $\left(\mathrm{HCO}_{3}^{-}\right)$transport in highly purified canalicular (c) and basolateral (bl) rat liver plasma membrane (LPM) vesicles. The data provide direct evidence for the presence of an electroneutral $\mathrm{Cl}^{-}: \mathrm{HCO}_{3}^{-}$ exchange in cLPM but not in blLPM vesicles. In addition, a separate $\mathrm{Cl}^{-}$conductive channel could also be identified in cLPM vesicles. These findings permit a unifying hypothesis to be proposed for the genesis of BAIF in rat liver and provide definitive support for models based on indirect observations in the isolated perfused rat liver $(5,9-11)$, and in isolated hepatocytes (16). Furthermore, the basic mechanisms involved in hepatic bile formation appear similar to anion transport processes initially observed in intestinal and renal epithelial cells (17-21). Part of this work has been presented in preliminary form (22).

\section{Methods}

Materials. Chlorine-36 $\left({ }^{36} \mathrm{Cl}^{-}\right)$was obtained as a $0.2-3.0 \mathrm{M} \mathrm{HCl}$ solution from New England Nuclear (Boston, MA). This radioactive

1. Abbreviations used in this paper: BADF, bile acid-dependent bile flow; BAIF, bile acid-independent bile flow; bILPM (vesicles), basolateral liver plasma membrane (vesicles); cLPM (vesicles), canalicular liver plasma membrane (vesicles); DIDS, 4,4'-diisothiocyano-2,2'-disulfonic acid stilbene; FCCP, carbonyl cyanide $p$-(trifluoromethoxy)-phenylhydrazone; SIM, standard incubation medium; SITS, 4-acetamido-4'isothiocyano-2,2'-disulfonic acid stilbene; SMS, standard membrane suspension; $\mathrm{TMA}^{+}$, tetramethylammonium. 
$\mathrm{HCl}$ solution was neutralized with tetramethylammonium hydroxide (TMA) to a pH of 7.5 before use. 4,4'-diisothiocyano-2,2'-disulfonic acid stilbene (DIDS) and 4-acetamido-4'-isothiocyano-2,2'-disulfonic acid stilbene (SITS) were purchased from Pierce Chemical Co. (Rockford, IL). Carbonyl cyanide $p$-(trifluoromethoxy)-phenylhydrazone (FCCP) was from Aldrich Chemical Co., Milwaukee, WI. Furosemide and amiloride were gifts from Hoechst-Roussel Pharmaceuticals (Summerville, NJ) and the Merck Sharp \& Dohme Research Laboratories (Rahway, NJ), respectively. All other chemicals and reagents were obtained either from Sigma Chemical Co. (St. Louis, MO), Baker Chemical Co. (Phillipsburg, NJ), or Schwarz/Mann Inc. (Spring Valley, NY).

Animals. Male Sprague-Dawley rats (Charles River Breeding Laboratories, Inc., Wilmington, MA) weighing $200-250 \mathrm{~g}$ were used throughout this study. The animals had free access to water, were fed Purina Rodent Chow (Ralston Purina Co., St. Louis, MO) ad lib. and were housed in a constant temperature-humidity environment with alternating 12 -h light (7 a.m.-7 p.m.) and dark cycles. Fed animals were regularly killed by decapitation between 7:30 and 8:30 a.m.

Isolation of CLPM and blLPM vesicles. The methods for isolation of the CLPM and bILPM subfractions as well as their morphologic and biochemical characterization are described in detail elsewhere (23). In brief, a canalicular enriched "mixed LPM" subfraction was first separated out of a "crude nuclear pellet" by rate zonal floatation (44\%: $36.5 \%$, wt/wt, sucrose density interface) in the TZ-28 (DuPont Instruments, Sorvall Biomedical Div., Newtown, CT) zonal rotor. After tight homogenization (type B Dounce homogenizer, 50 up and down strokes) the vesiculated CLPM and bILPM were separated from the "mixed LPM" by high-speed centrifugation $\left(195,200 g_{\text {ave }}\right.$ for $\left.3 \mathrm{~h}\right)$ through a three-step sucrose gradient $(31 \%, 34 \%$, and $38 \%$, wt/wt). cLPM were recovered from the top of the $31 \%$ sucrose layer and blLPM were harvested from the $34 \%: 38 \%$ sucrose density interface. Both LPM subfractions were collected at $105,000 \mathrm{~g}_{\text {ave }}$ for $60 \mathrm{~min}$ and resuspended in the appropriate membrane suspension buffers (see below).

Characteristics of the isolated LPM subfractions. The degree of purification of CLPM and blLPM vesicles was extensively analyzed by intracellular and plasma membrane marker enzyme activities. These studies indicated minor contamination of both LPM subfractions with intracellular organelles and virtually complete separation of bILPM from cLPM vesicles as reflected by the absence of $\mathrm{Na}^{+} \mathrm{K}^{+}$-ATPaseand glucagon-stimulatable adenylate cyclase activities or intact secretory component in CLPM (23). In contrast, the blLPM subfraction is contaminated with cLPM by $\sim 10 \%$. Transmission electron microscopy revealed that both CLPM and bILPM are composed of membrane vesicles, although bILPM vesicles still contain unbroken lateral membrane sheets (23). Correspondingly, intravesicular volumes are approximately twofold higher in $\mathrm{CLPM}\left(\sim 2 \mu \mathrm{l} \cdot \mathrm{mg}^{-1}\right.$ protein) than in blLPM $\left(\sim 1 \mu \mathrm{l} \cdot \mathrm{mg}^{-1}\right.$ protein $)$ as calculated from equilibrium uptakes of $\left[{ }^{14} \mathrm{C}\right]$ glucose that did not bind to any extent to the isolated membrane vesicles (8). Finally, freeze fracture analysis revealed that $\sim 80 \%$ of the cLPM vesicles exhibit "right side out" configuration, in which the extravesicular membrane face corresponds to the bile luminal surface in vivo (8).

Chloride $\left({ }^{36} \mathrm{Cl}^{-}\right)$uptake studies. The experimental design used in this study to determine the effect of $\mathrm{pH}$ and $\mathrm{HCO}_{3}^{-}$on $\mathrm{Cl}^{-}$.transport closely paralleled studies previously performed in rabbit ileal and Necturus renal brush border vesicles $(17,24)$. In order to preload the vesicles with $\mathrm{HCO}_{3}^{-}(50 \mathrm{mM})$, freshly isolated membrane vesicles were resuspended by tight homogenization (10 up and down strokes, type B glass-glass Dounce homogenizer) in $150 \mathrm{mM}$ sucrose, $100 \mathrm{mM}$ TMA gluconate, $50 \mathrm{mM}$ choline bicarbonate, $35 \mathrm{mM}$ Tris, $35 \mathrm{mM}$ Hepes, $0.2 \mathrm{mM}$ Ca-gluconate, and $5 \mathrm{mM}$ Mg-gluconate, $\mathrm{pH}$ 7.7. This buffer system will be referred to as "bicarbonate standard membrane suspension" ( $\mathrm{HCO}_{3}^{-}$-SMS, $\left.\mathrm{pH} 7.7\right)$ medium throughout this study. In experiments, where the vesicles were preloaded differently, the composition of the membrane resuspension buffers will be detailed in the corresponding figure legends. Routinely, the freshly isolated membrane vesicles were frozen and stored in liquid nitrogen $\left(-70^{\circ} \mathrm{C}\right.$; protein concentration $>5 \mathrm{mg} / \mathrm{ml}$ ) for up to $4 \mathrm{~d}$ without loss of transport function for ${ }^{36} \mathrm{Cl}^{-}$.

For measuring uptake of ${ }^{36} \mathrm{Cl}^{-}$, the frozen vesicle suspensions were quickly thawed in a $37^{\circ} \mathrm{C}$ water bath, diluted to the desired protein concentration and revesiculated by repeated (10 times) passage through a 25 -gauge needle. $10 \mu \mathrm{l}(45-70 \mu \mathrm{g}$ of protein) of this membrane vesicle suspension was then incubated at $25^{\circ} \mathrm{C}$ in $90 \mu \mathrm{l}$ of incubation medium. In the presence of an outwardly directed simultaneous $\mathrm{pH}$ and $\mathrm{HCO}_{3}^{-}$gradient, the incubation medium consisted of a $\mathrm{HCO}_{3}^{-}$-free buffer, pH 6.0, containing $184 \mathrm{mM}$ sucrose, $100 \mathrm{mM}$ TMA gluconate, $30 \mathrm{mM}$ Tris, $14 \mathrm{mM}$ Hepes, $90 \mathrm{mM}$ morpholino-ethane-sulfonic acid, $0.2 \mathrm{mM}$ Ca-gluconate and $5 \mathrm{mM} \mathrm{Mg-gluconate.} \mathrm{This} \mathrm{solution} \mathrm{will} \mathrm{be}$ called "standard incubation medium," pH 6.0 (SIM, pH 6.0) throughout this study. Chloride in the desired concentrations was added to all incubation media as a neutral TMA ${ }^{36} \mathrm{Cl}^{-}$solution. Routinely, the reaction mixtures were gassed with $95 \% \mathrm{~N}_{2}, 5 \% \mathrm{CO}_{2}$ to maintain the $\mathrm{pH}$ during the whole incubation period. If no $\mathrm{HCO}_{3}^{-}$was present in the reaction mixture gassing was done with $100 \% \mathrm{~N}_{2}$. After incubation of the vesicles for the indicated time intervals, uptake of ${ }^{36} \mathrm{Cl}^{-}$was terminated by the addition of $3.5 \mathrm{ml}$ of ice-cold stop solution consisting of $204 \mathrm{mM}$ sucrose, $150 \mathrm{mM}$ K-gluconate, $0.2 \mathrm{mM}$ Ca-gluconate, 5 $\mathrm{mM}$ Mg-gluconate, $10 \mathrm{mM}$ Hepes/Tris, $\mathrm{pH}$ 7.5. Membrane vesicleassociated ligand was separated from free ligand by immediate rapid filtration $(1 \mathrm{ml} / \mathrm{s})$ through a $0.45-\mu \mathrm{m}$ Millipore filter (Millipore/ Continental Water Systems, Bedford, MA), which had been presoaked in cold deionized water. The filter was washed twice with $3.5 \mathrm{ml}$ of stop solution, dissolved in Redisolv HP (Beckman Instruments, Inc., Palo Alto, CA) and counted in a Beckman LS 2000 liquid scintillation counter. Nonspecific binding to the filter and the membrane vesicles was determined in each experiment by addition of cold incubation solution and cold stop solution to $10 \mu \mathrm{l}$ of membrane suspension kept at $0-4^{\circ} \mathrm{C}$. This membrane/filter blank was subtracted from all determinations. Unless otherwise indicated all experimental data were obtained from triplicate analysis of two or more separate membrane preparations. Statistical significance was determined by analysis of variance with two-way layout.

\section{Results}

Direct evidence for $\mathrm{Cl}^{-}: \mathrm{HCO}_{3}^{-}$and $\mathrm{Cl}^{-}: \mathrm{OH}^{-}$exchange in cLPM vesicles. The effects of the gradients of in to out $\mathrm{pH}$ and $\mathrm{HCO}_{3}^{-}$on uptake of $\mathrm{Cl}^{-}(5 \mathrm{mM})$ into cLPM vesicles are demonstrated in Fig. 1. With the vesicles preloaded with $\mathrm{pH}$ 7.7 buffers, the uptake of $\mathrm{Cl}^{-}$was stimulated twofold when incubated at $\mathrm{pH} 6.0$ (7.7 in/6.0 out) as compared with pHequilibrated conditions ( $7.7 \mathrm{in} / 7.7$ out). If $50 \mathrm{mM} \mathrm{HCO}-$ was additionally present within the vesicles, the same in to out $\mathrm{pH}$ gradients $(7.7,50 \mathrm{mM} \mathrm{HCO}-\overline{3}$ in/6.0, $0.9 \mathrm{mM} \mathrm{HCO}-\overline{\text { out}}$ ) further stimulated $\mathrm{Cl}^{-}$uptake up to three- to fourfold above values obtained under $\mathrm{pH}$ - and $\mathrm{HCO}_{3}^{-}$-equilibrated conditions $\left(7.7,50 \mathrm{mM} \mathrm{HCO}_{3}^{-}\right.$in = out). Furthermore, $\mathrm{Cl}^{-}$was transiently accumulated within the vesicles to $\sim 2.5$ times above $\mathrm{Cl}^{-}$ equilibrium values at $180 \mathrm{~min}$ (overshoot phenomenon). No significant differences in $\mathrm{Cl}^{-}$uptake were observed between the two pH-equilibrated conditions $7.7 / 7.7$ or $6.0 / 6.0$ (data not shown). Thus, it is the $\mathrm{pH}$ gradient rather than the $\mathrm{pH}$ per se that markedly accelerated the uptake of $\mathrm{Cl}^{-}$. The additional stimulatory effect of an in to out $\mathrm{HCO}_{3}^{-}$gradient indicates that $\mathrm{HCO}_{3}^{-}$is favored over $\mathrm{OH}^{-}$for exchange with extravesicular $\mathrm{Cl}^{-}$. This conclusion is not invalidated by the observation that $\mathrm{HCO}_{3}^{-}$did not stimulate $\mathrm{Cl}^{-}$uptake under $\mathrm{pH}$-equilibrated conditions ( $\mathrm{O}$ in Fig. 1) inasmuch as the high extravesicular concentration of $\mathrm{HCO}_{3}^{-}(50 \mathrm{mM})$ might have effectively competed with chloride for uptake. 


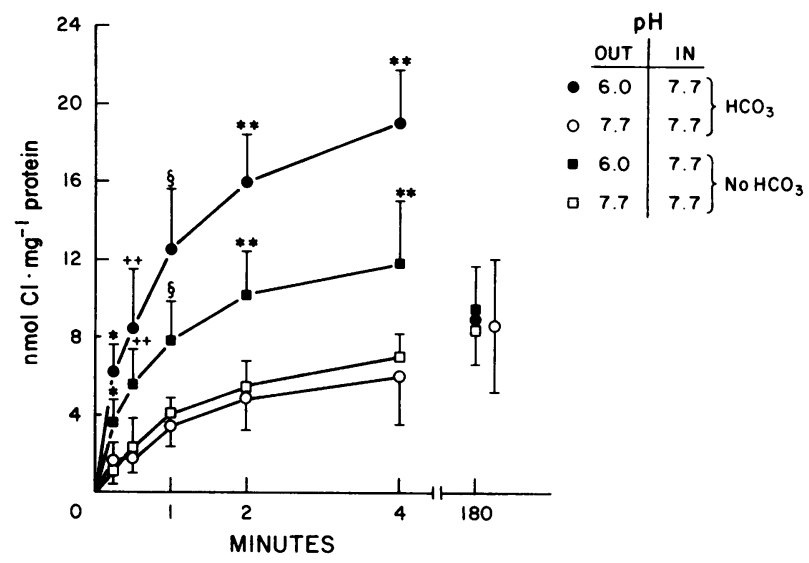

Figure 1. Effects of outwardly directed $\mathrm{pH}$ and $\mathrm{HCO}_{3}^{-}$gradients on chloride uptake into cLPM vesicles. The vesicles were preloaded with a pH 7.7 buffer either in the presence of $50 \mathrm{mM} \mathrm{HCO}_{3}^{-}$(resuspension in $\mathrm{HCO}_{3}^{-}$-SMS) or in the absence of $\mathrm{HCO}_{3}^{-}$(resuspension in $150 \mathrm{mM}$ sucrose, $115 \mathrm{mM}$ TMA gluconate, $70 \mathrm{mM}$ Tris, $70 \mathrm{mM}$ Hepes, 0.2 $\mathrm{mM}$ Ca-gluconate, and $5 \mathrm{Mg}$-gluconate) as described in Methods. Chloride $(5 \mathrm{mM})$ uptake was determined at $25^{\circ} \mathrm{C}$ by diluting the vesicles 10 -fold into a gassed $\left(95 \% \mathrm{~N}_{2}, 5 \% \mathrm{CO}_{2}\right.$ in the presence of $\mathrm{HCO}_{3}^{-} ; 100 \% \mathrm{~N}_{2}$ in the absence of $\mathrm{HCO}_{3}^{-}$) incubation medium containing ${ }^{36} \mathrm{Cl}^{-}$. Under $\mathrm{pH}$ (pH 7.7 in = out; $\square$ ) or $\mathrm{pH}$ and $\mathrm{HCO}_{3}^{-}$ (pH 7.7, $50 \mathrm{mM} \mathrm{HCO}-$ in = out; 0 ) equilibrated conditions, the composition of membrane suspension media and incubation media was identical (except for ${ }^{36} \mathrm{Cl}^{-}$). In the presence of outwardly directed pH (7.7 in/6.0 out; $\square$ ) or pH and $\mathrm{HCO}_{3}^{-}$(pH 7.7, 50 mM HCO- in/ $\mathrm{pH} 6.0,0.91 \mathrm{mM} \mathrm{HCO}_{3}^{-}$out; $\bullet$ ) gradients the vesicles were incubated in $\mathrm{HCO}_{3}^{-}$free "standard incubation medium" of pH 6.0 (SIM, pH 6.0 ), the composition of which is given in Methods. Data represent the mean $\pm S D$ of nine determinations in three separate membrane vesicle preparations. Levels of significant differences are $P<0.025$ (*), $P<0.05(++), P<0.005)(\S)$, and $P<0.001(* *)$, respectively.

The presence of a $\mathrm{Cl}^{-}: \mathrm{HCO}_{3}^{-}$and $\mathrm{Cl}^{-}: \mathrm{OH}^{-}$exchanger in cLPM vesicles is further supported by the finding that DIDS, the most potent inhibitor of inorganic anion exchange in erythrocytes (25) and intestinal brush border membranes (17), completely inhibited the initial $\mathrm{pH}$ - and $\mathrm{HCO}_{3}^{-}$-stimulated uptake rates of $\mathrm{Cl}^{-}$(Fig. 2). However, after $30 \mathrm{~s}$ the inhibition of $\mathrm{Cl}^{-}$uptake was incomplete even with $5 \mathrm{mM}$ DIDS. These data suggest that, whereas initial uptake rates of $\mathrm{Cl}^{-}$were mainly due to DIDS-sensitive $\mathrm{Cl}^{-}: \mathrm{HCO}_{3}^{-}$and $\mathrm{Cl}^{-}: \mathrm{OH}^{-}$exchange, uptake at later time points proceeded to a significant extent via a DIDS-insensitive, most likely conductive, pathway. Indeed when $\mathrm{Cl}^{-}$uptake was investigated at $\mathrm{pH}$ equilibrium (7.5/7.5), the generation of an inside-positive $\mathrm{K}^{+}$diffusion potential by valinomycin $\left(\mathrm{K}^{+}\right.$out $>$in $; 100 \mathrm{mM}$ ) significantly stimulated $\mathrm{Cl}^{-}$uptake compared with $\mathrm{K}^{+}$-equilibrated conditions $\left(\mathrm{K}^{+}\right.$in = out, $100 \mathrm{mM}$; Fig. 3). However, this potential driven $\mathrm{Cl}^{-}$uptake could not be inhibited by DIDS. Thus, the previously demonstrated $\mathrm{pH}$ and $\mathrm{HCO}_{3}^{-}$gradient-stimulated, DIDS-sensitive $\mathrm{Cl}^{-}$uptake (Fig. 2) can be attributed to $\mathrm{Cl}^{-}$: $\mathrm{HCO}_{3}^{-}$and $\mathrm{Cl}^{-}: \mathrm{OH}^{-}$ex́change mechanisms. Because $\mathrm{HCO}_{3}^{-}$ appears to be favored over $\mathrm{OH}^{-}$for transcanalicular exchange with $\mathrm{Cl}^{-}$(Fig. 1), the term $\mathrm{Cl}^{-}: \mathrm{HCO}_{3}^{-}$exchange will be preferentially used subsequently.

Characteristics of the canalicular $\mathrm{Cl}^{-}: \mathrm{HCO}_{3}^{-}$exchange. As demonstrated in Fig. 4 the $\mathrm{pH}$ and $\mathrm{HCO}_{3}^{-}$gradient-stimulated initial $\mathrm{Cl}^{-}$uptake rates were temperature sensitive. Furthermore,

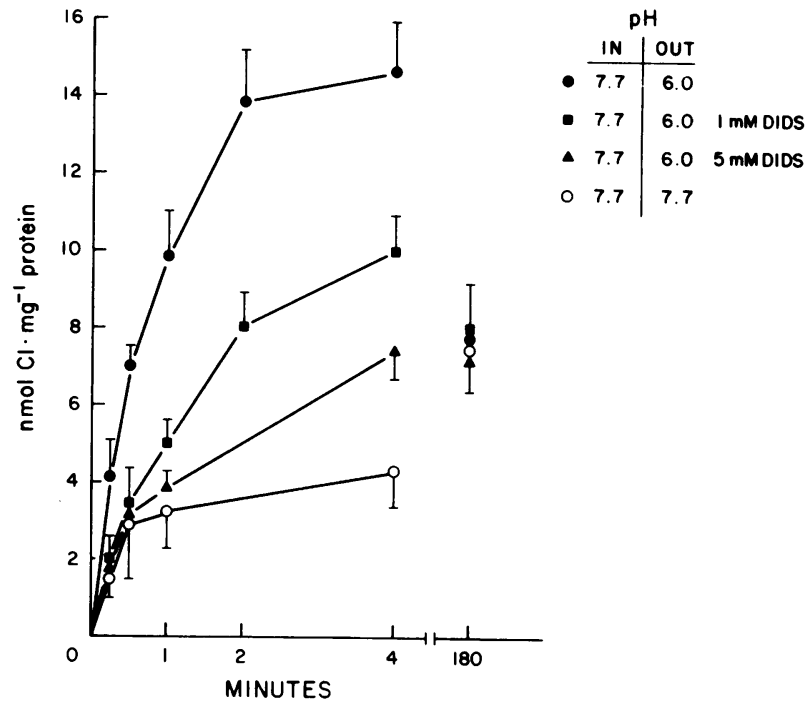

Figure 2. Effect of DIDS on pH- and $\mathrm{HCO}_{3}^{-}$-stimulated chloride uptake in cLPM vesicles. $\mathrm{HCO}_{3}^{-}(50 \mathrm{mM})$ preloaded cLPM vesicles $\left(\mathrm{HCO}_{3}^{-}\right.$-SMS, pH 7.7) were incubated in gassed $\left(95 \% \mathrm{~N}_{2}, 5 \% \mathrm{CO}_{2}\right)$ SIM, pH 6.0 in the presence $(\bullet, \triangle)$ and absence $(\bullet)$ of 1 and $5 \mathrm{mM}$ DIDS. The concentration of $\mathrm{Cl}^{-}$in the reaction mixture was $5 \mathrm{mM}$. Uptake of ${ }^{36} \mathrm{Cl}^{-}$in the absence of a pH and $\mathrm{HCO}_{3}^{-}$gradient (0) was determined by incubating the vesicles in $\mathrm{HCO}_{3}^{-}-\mathrm{SMS}, \mathrm{pH}$ 7.7. Because of DIDS sensitivity to light, all experiments using this compound were performed with minimal exposure to light. Data represent the mean $\pm \mathrm{SD}$ of six determinations in two separate membrane preparations.

the DIDS-sensitive portions of $\mathrm{Cl}^{-}$uptake exhibited linearity with incubation time up to $\sim 6 \mathrm{~s}$. Based on these results 4-s uptake values were chosen for the kinetic studies.

The dependence of the $\mathrm{pH}$ and $\mathrm{HCO}_{3}^{-}$gradient-driven initial $\mathrm{Cl}^{-}$uptake rates on increasing concentrations of $\mathrm{Cl}^{-}$is illustrated in Fig. 5. A large component of $\mathrm{Cl}^{-}$uptake, especially at higher $\mathrm{Cl}^{-}$concentrations was DIDS insensitive and nonsaturable. However, when the DIDS-insensitive uptake (O) was subtracted from total uptake (๑), $\mathrm{Cl}^{-}$uptake resolved into a

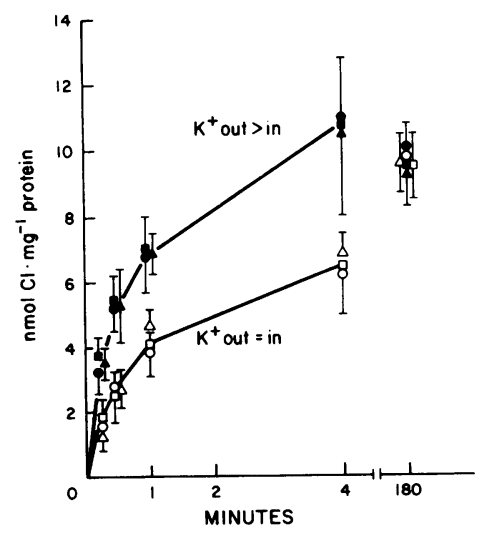

Figure 3. Effect of a valinomycin-induced $\mathrm{K}^{+}$diffusion potential (inside positive) on chloride uptake into cLPM vesicles. The vesicles were resuspended (preloaded) in $150 \mathrm{mM}$ sucrose, $0.2 \mathrm{mM}$ Ca-gluconate, $5 \mathrm{mM} \mathrm{Mg-gluconate,}$ 70 mM Hepes-TMA $\mathrm{OH}^{-}$ (pH 7.5) and either 100

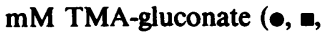
$\triangle)$ or $100 \mathrm{mM} \mathrm{K-gluconate}$ $(0, \square, \Delta)$. Valinomycin $(10$ $\mu \mathrm{g} / \mathrm{mg}$ protein) was added to all vesicle suspensions 2-5 $\mathrm{min}$ before the

reactions were started. Incubations were done in $140 \mathrm{mM}$ sucrose, $0.2 \mathrm{mM}$ Ca-gluconate, $5 \mathrm{mM}$ Mg-gluconate, $70 \mathrm{mM}$ Hepes-TMA$\mathrm{OH}^{-}$(pH 7.5), $100 \mathrm{mM}$ K-gluconate, $5 \mathrm{mM}^{36} \mathrm{Cl}^{-}$and either 0

$(0, \bullet), 1(\square, \triangleleft)$, or $5(\Delta, \Delta) \mathrm{mM}$ DIDS. Data represent the mean \pm SD of six determinations in two separate membrane preparations. 


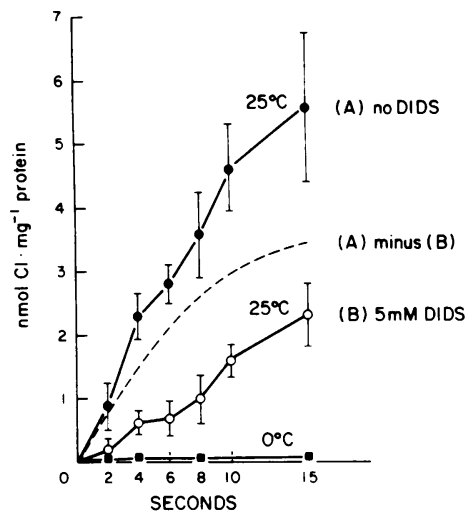

Figure 4. Initial rates of pH- and bicarbonate-stimulated chloride uptake in cLPM vesicles. $\mathrm{HCO}_{3}^{-}$preloaded vesicles $\left(\mathrm{HCO}_{3}^{-}\right.$-SMS, $\left.\mathrm{pH} 7.7\right)$ were incubated in $\mathrm{HCO}_{3}^{-}$-free SIM, pH 6.0, containing ${ }^{36} \mathrm{Cl}^{-}(5 \mathrm{mM})$ and either none $(\bullet)$ or $5 \mathrm{mM}(0)$ DIDS (mean \pm SD; $n=6$ ). The dotted line represents the DIDS-sensitive initial uptake rates at $25^{\circ} \mathrm{C}$ that are due to $\mathrm{Cl}^{-}: \mathrm{HCO}_{3}^{-}$(and $\mathrm{Cl}^{-}: \mathrm{OH}^{-}$) exchange. For comparison the $\mathrm{pH}$ and $\mathrm{HCO}_{3}^{-}$-stimulated ${ }^{36} \mathrm{Cl}^{-}$uptake was also determined at $0^{\circ} \mathrm{C}(\boldsymbol{\square})$ in one experiment.

saturable function of the $\mathrm{Cl}^{-}$concentration (*, ---). A Lineweaver-Burke plot analysis of the DIDS-sensitive component of $\mathrm{Cl}^{-}$uptake revealed an apparent $K_{\mathrm{m}}$ of $6.3 \mathrm{mM}$ and a $V_{\max }$ of $51 \mathrm{nmol} \cdot \mathrm{min}^{-1} \cdot \mathrm{mg}^{-1}$ protein.

The effects of various inhibitors of carrier-mediated transport on $\mathrm{pH}$ and $\mathrm{HCO}_{3}^{-}$gradient-stimulated $\mathrm{Cl}^{-}$uptake into cLPM vesicles are summarized in Table I. DIDS and SITS were the most effective inhibitors (as in erythrocytes and intestinal brush border; 17, 25). Probenecid, the "standard" inhibitor of carrier-mediated organic anion transport in the kidney (26) was less effective, suggesting that the canalicular $\mathrm{Cl}^{-}: \mathrm{HCO}_{3}^{-}$exchanger does not primarily function as an organic anion transporter. Amiloride, a competitive inhibitor of renal and intestinal $\mathrm{Na}^{+}: \mathrm{H}^{+}$exchange $(27,28)$, had no effects as expected. Although their exact mechanisms of action are unclear at present, the observed partial inhibitory effects of furosemide and bumetanide are consistent with their effects on carrier-mediated $\mathrm{Cl}^{-}$transport in intestinal brush border membranes (17) and erythrocytes (29). None of the tested compounds affected equilibrium $\mathrm{Cl}^{-}$uptake at $180 \mathrm{~min}$, indicating the absence of nonspecific toxic membrane injury under all conditions studied. In summary, the observed effects of the various inhibitors of $\mathrm{pH}$ - and $\mathrm{HCO}_{3}^{-}$-stimulated $\mathrm{Cl}^{-}$ uptake into CLPM vesicles further support the concept of a carrier-mediated $\mathrm{Cl}^{-}: \mathrm{HCO}_{3}^{-}$exchange in bile canalicular membranes of rat liver.

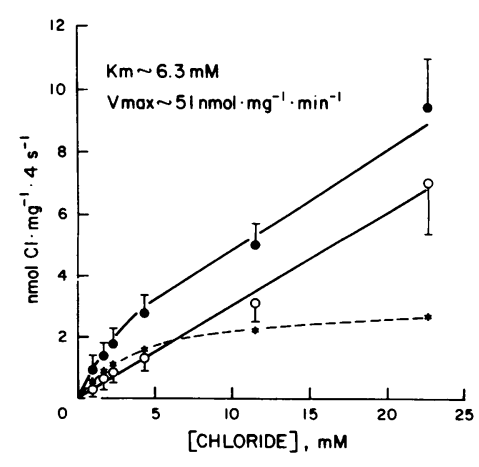

Figure 5. Kinetics of $\mathrm{Cl}^{-}$: $\mathrm{HCO}_{3}^{-}$exchange in CLPM vesicles. 4-s uptakes of increasing concentrations of chloride into $\mathrm{HCO}_{3}^{-}(50$ $\mathrm{mM}$ ) preloaded CLPM vesicles $\left(\mathrm{HCO}_{3}^{-}-\mathrm{SMS}, \mathrm{pH} 7.7\right)$ were determined in gassed $\left(95 \% \mathrm{~N}_{2}, 5 \% \mathrm{CO}_{2}\right)$ SIM, pH 6.0 in the presence (o) and absence $(\bullet)$ of $5 \mathrm{mM}$ DIDS. The DIDS-sensitive initial uptake rates exhibited saturation with increasing concentrations of $\mathrm{Cl}^{-}(*--*)$. The data represent the mean \pm SD of eight determinations in two separate membrane preparations. The lines through the various points represent a visual fit.
Table I. Effects of Membrane Transport Inhibitors on $\mathrm{pH}$ - and $\mathrm{HCO}_{3}^{-}$-stimulated $\mathrm{Cl}^{-}$Uptake in cLPM Vesicles*

\begin{tabular}{|c|c|c|c|}
\hline & ${ }^{36} \mathrm{Cl}^{-}$uptake & & \\
\hline & $10 \mathrm{~s}$ & $\%$ & $180 \mathrm{~min}$ \\
\hline & $\mathrm{nmol} \cdot \mathrm{mg}^{-1}$ protein & & $n m o l \cdot m g^{-1}$ protein \\
\hline Controls & $4.3 \pm 0.8$ & $(100)$ & $9.8 \pm 0.9$ \\
\hline Amiloride & $4.4 \pm 1.1 \ddagger$ & (102) & $10.0 \pm 1.4$ \\
\hline Bumetanide & $3.2 \pm 0.5^{*}$ & (74) & $10.7 \pm 2.0$ \\
\hline Furosemide & $2.9 \pm 0.4^{\prime \prime}$ & (67) & $10.5 \pm 0.9$ \\
\hline Probenecid & $2.7 \pm 0.4^{\prime \prime}$ & (63) & $10.5 \pm 1.0$ \\
\hline SITS & $2.2 \pm 0.9^{\prime \prime}$ & (51) & $9.7 \pm 1.6$ \\
\hline DIDS & $1.3 \pm 0.3^{\| \prime}$ & (30) & $9.7 \pm 1.3$ \\
\hline
\end{tabular}

* The vesicles were preloaded with $\mathrm{HCO}_{3}^{-}-\mathrm{SMS}$, $\mathrm{pH} 7.7$, and incubated in SIM, $\mathrm{pH} 6.0$, containing ${ }^{36} \mathrm{Cl}^{-}(5 \mathrm{mM})$. The various inhibitors $(1 \mathrm{mM})$ were directly added to the membrane suspensions from stock solutions prepared in $\mathrm{HCO}_{3}^{-}-\mathrm{SMS}$. Data represent the mean \pm SD of eight determinations in two different membrane preparations. Levels of significance with respect to controls are: not significant ( $\ddagger), P<0.005(\S)$, and $P<0.001$ ("), respectively. In addition, the effects of DIDS, but not those of SITS, are significantly different from probenecid $(P<0.001)$.

The effects of various organic and inorganic anions on $\mathrm{pH}$ and $\mathrm{HCO}_{3}^{-}$-stimulated $\mathrm{Cl}^{-}$uptake into $\mathrm{CLPM}$ vesicles are given in Table II. Neither sulfate nor $p$-aminohippuric acid, lactate, aspartate, and glutamate $(20 \mathrm{mM})$ had any cis-inhibitory effect on initial $(8 \mathrm{~s})$ uptake rates of $\mathrm{Cl}^{-}$. Although significantly different from controls, the effects of acetate are too small for being attributable to co-transport under the given experimental conditions (30). In contrast, chloride demonstrated cis-inhibition to the extent that was expected theoretically (30). In addition, nitrate may be a co-substrate for the canalicular $\mathrm{Cl}^{-}$: $\mathrm{HCO}_{3}^{-}$exchange system as has also been observed in the

Table II. Effects of Various Organic and Inorganic Anions on $\mathrm{pH}$ - and $\mathrm{HCO}_{3}^{-}$-stimulated $\mathrm{Cl}^{-}$Uptake in cLPM Vesicles*

\begin{tabular}{ll}
\hline & ${ }^{36} \mathrm{Cl}^{-}$uptake \\
\hline Controls & $\%$ \\
$p$-Aminohippuric acid & 100 \\
Lactate & $102 \pm 23 \ddagger$ \\
Aspartate & $100 \pm 23 \ddagger$ \\
Sulfate & $109 \pm 21 \ddagger$ \\
Glutamate & $98 \pm 18 \ddagger$ \\
Acetate & $93 \pm 16 \ddagger$ \\
Chloride & $85 \pm 12 \S$ \\
Nitrate & $41 \pm 11^{11}$ \\
\hline
\end{tabular}

* $\mathrm{HCO}_{3}^{-}$-SMS, pH 7.7, preloaded vesicles were incubated in SIM, pH 6.0 , containing either $5 \mathrm{mM} \mathrm{M}^{36} \mathrm{Cl}^{-}$alone (= controls) or, in addition, $20 \mathrm{mM}$ of the indicated anions. Uptake of ${ }^{36} \mathrm{Cl}^{-}$was determined at 8 s. Data represent the mean $\pm \mathrm{SD}$ of eight determinations in two separate membrane preparations. No effects of the various anions on equilibrium ${ }^{36} \mathrm{Cl}^{-}$uptake at $180 \mathrm{~min}$. were observed. Levels of significance with respect to controls are: not significant $(\ddagger), P<0.01$ (§), and $P<0.001$ ("), respectively. 


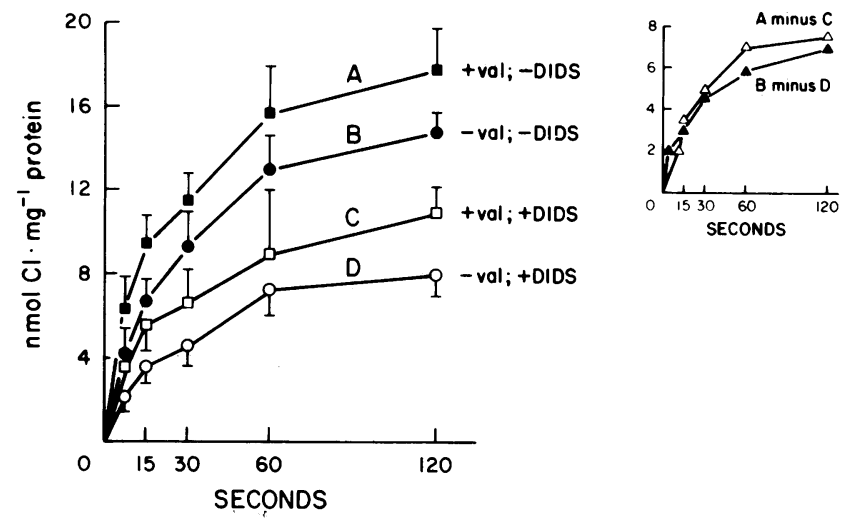

Figure 6. Effect of valinomycin-induced membrane potential changes on canalicular $\mathrm{Cl}^{-}: \mathrm{HCO}_{3}^{-}$exchange. $\mathrm{HCO}_{3}^{-} \mathrm{SMS}$, pH 7.7, preloaded cLPM vesicles were treated with valinomycin in ethanol $(10 \mu \mathrm{g} / \mathrm{mg}$ protein; $\square, \square)$ or the equivalent amount of ethanol $(0.3 \%)$ only $(0, \bullet)$. The vesicles were then incubated in SIM, pH 6.0 containing $100 \mathrm{mM}$ K-gluconate instead of TMA-gluconate. ${ }^{36} \mathrm{Cl}^{-}(5 \mathrm{mM})$ uptake was determined in the presence $(0, \square)$ and absence $(\bullet,-)$ of $5 \mathrm{mM}$ DIDS. Data represent the mean $\pm S D$ of six determinations in two separate membrane preparations. Inset demonstrates that valinomycin has no effect on the DIDS-sensitive portion of $\mathrm{pH}$ and $\mathrm{HCO}_{3}^{-}$-driven $\mathrm{Cl}^{-}$ uptake.

erythrocyte (25) and the intestine (17). These studies complement the data obtained with the various membrane transport inhibitors (Table I) and indicate that, unlike in the dog renal microvillus membrane (20) but similar to the rabbit ileal brush border (17), the canalicular $\mathrm{Cl}^{-}: \mathrm{HCO}_{3}^{-}$exchanger in rat liver transports neither sulfate nor organic anions. Parenthetically, the addition of taurocholate or ursodeoxycholate $(100 \mu \mathrm{M})$ to the reaction mixture had no effects on the $\mathrm{pH}$ and $\mathrm{HCO}_{3}^{-}$ gradient-stimulated uptake of $\mathrm{Cl}^{-}$into cLPM vesicles (data not shown).

Finally, we investigated the electrogenicity of the DIDSsensitive component of the $\mathrm{pH}$ - and $\mathrm{HCO}_{3}^{-}$-stimulated $\mathrm{Cl}^{-}$ uptake in CLPM vesicles. As demonstrated in Fig. 6, when a valinomycin-induced inside-positive $\mathrm{K}^{+}$diffusion potential was superimposed upon an outwardly directed $\mathrm{pH}$ and $\mathrm{HCO}_{3}^{-}$ gradient, overall $\mathrm{Cl}^{-}$uptake was stimulated (curves $A$ and $C$ ) compared with the absence of valinomycin (curves $B$ and $D$ ). However, the DIDS-sensitive portion of the $\mathrm{pH}$ - and $\mathrm{HCO}_{3}^{-}$-stimulated $\mathrm{Cl}^{-}$uptake was not affected by the imposed membrane potential changes (Fig. 6 , inset; $\Delta$ compared with $\triangle)$. These data are consistent with an electroneutral 1:1 exchanger of $\mathrm{Cl}^{-}$and $\mathrm{HCO}_{3}^{-}$across the canalicular membrane.

Distribution of $\mathrm{Cl}^{-}: \mathrm{HCO}_{3}^{-}$exchange on the various surface domains of hepatocytes. To investigate whether the identified rat liver $\mathrm{Cl}^{-}: \mathrm{HCO}_{3}^{-}$exchanger is selectively confined to the canalicular pole or present on all surface domains of hepatocytes, we directly compared the $\mathrm{pH}$ and $\mathrm{HCO}_{3}^{-}$gradient-driven $\mathrm{Cl}^{-}$uptake in cLPM and blLPM isolated simultaneously from the same homogenate. In contrast to cLPM, intravesicular $\mathrm{Cl}^{-}$ did not overshoot the equilibrium values in blLPM although there was a constant, albeit small, stimulation of $\mathrm{Cl}^{-}$uptake by the in to out $\mathrm{pH}$ and $\mathrm{HCO}_{3}^{-}$gradient (Fig. 7). These data are in contrast to those of our previous studies with alanine and taurocholate where transport systems are present in both LPM subfractions and initial solute uptake rates therefore were similar in CLPM and blLPM despite the twofold differences in their intravesicular volumes (8). Based on these earlier studies with different substrates as well as the fact that $\sim 20 \%$ of the total intravesicular space of blLPM represents contamination with CLPM vesicles (23), the data presented in Fig. 7 suggest that the $\mathrm{Cl}^{-}: \mathrm{HCO}_{3}^{-}$exchange system is not present in the basolateral domain of rat hepatocytes.

Effects of inwardly directed $\mathrm{Na}^{+}$gradients on $\mathrm{Cl}^{-}$uptake in CLPM and blLPM vesicles. Fig. 8 summarizes results of studies designed to determine whether sodium-chloride cotransport mechanisms exist in canalicular and/or basolateral rat liver plasma membranes. In these experiments the intravesicular uptake of chloride was compared in the presence of inwardly directed $\mathrm{Na}^{+}, \mathrm{K}^{+}, \mathrm{Na}^{+}$and $\mathrm{K}^{+}$, or $\mathrm{TMA}^{+}$gradients. To control for the influence of the electrical membrane potential, the incubations were done under $\mathrm{pH}$-equilibrated conditions (high ionic strength buffer) and in the presence of the proton ionophore FCCP. As shown in Fig. 8, under these conditions neither $\mathrm{Na}^{+}$nor $\mathrm{K}^{+}$nor both together exhibited any stimulation of initial $\mathrm{Cl}^{-}$uptake rates when compared with $\mathrm{TMA}^{+}$. These results were the same in CLPM and blLPM. Hence, no evidence was found for the presence of a sodiumchloride co-transport system in rat liver plasma membranes. These findings are in agreement with recent studies in the isolated perfused liver and with cultured hepatocytes (31).

\section{Discussion}

Recent indirect studies in the isolated perfused liver have suggested that active transhepatocyte secretion of both $\mathrm{Cl}^{-}$and
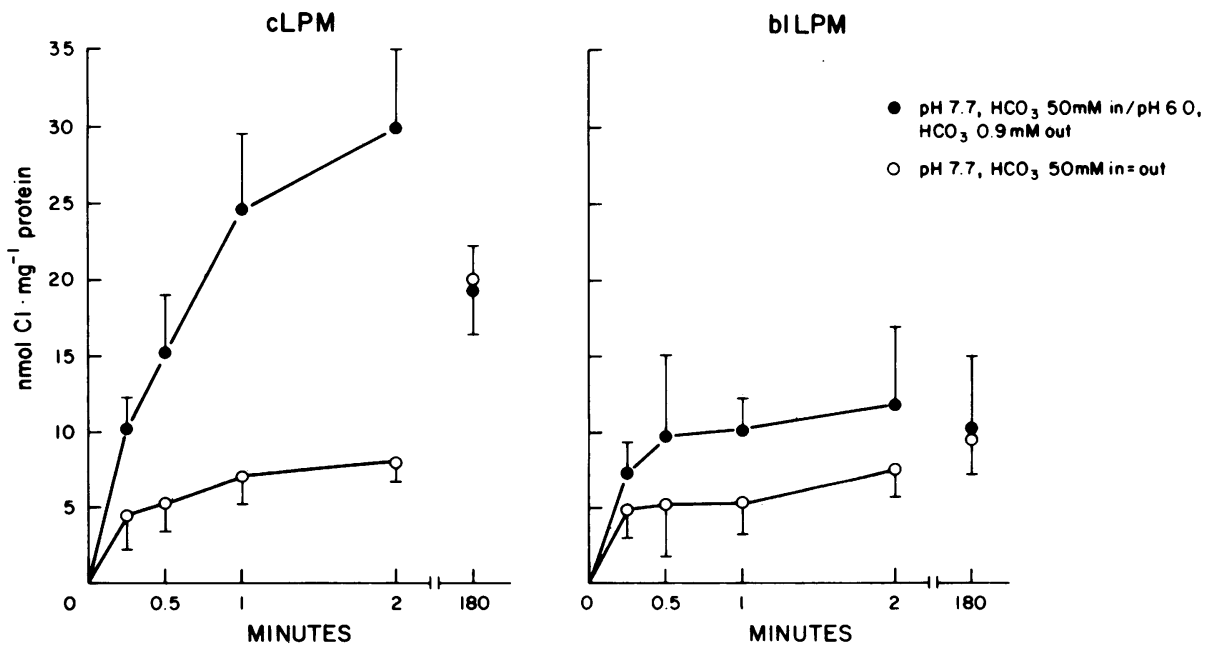

Figure 7. Comparison of $\mathrm{pH}-$ and $\mathrm{HCO}_{3}^{-}$-driven chloride uptake between CLPM and blLPM vesicles. The vesicles were preloaded with $\mathrm{HCO}_{3}^{-}$-SMS, pH 7.7, and incubated either in $\mathrm{HCO}_{3}^{-}$-free SIM, pH $6.0(\bullet)$, or $\mathrm{HCO}_{3}^{-}$-SMS, pH 7.7 (o). $\mathrm{Cl}^{-}$was present in a concentration of $11.4 \mathrm{mM}$. Data represent the mean \pm SD of four determinations in two separate membrane preparations. 

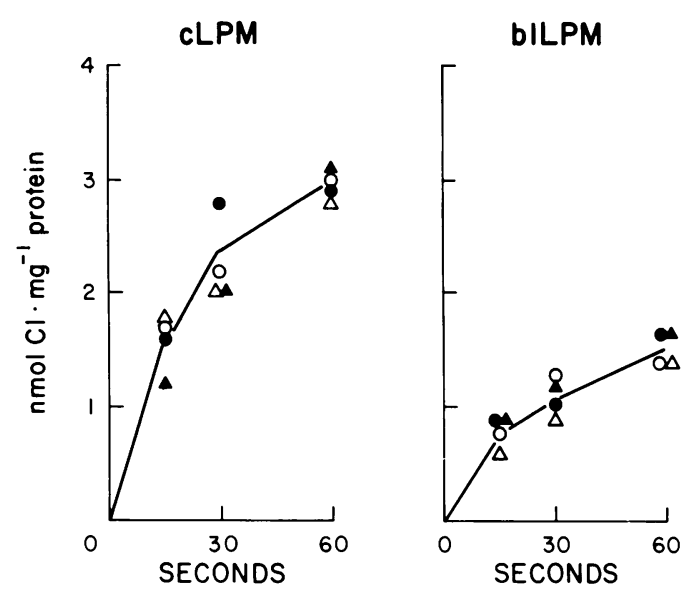

Figure 8. Effect of inwardly directed cation gradients on chloride uptake in CLPM and bILPM vesicles. Membrane vesicles were prepared in $250 \mathrm{mM}$ sucrose, $0.2 \mathrm{mM}$ Ca-gluconate, $5 \mathrm{mM} \mathrm{Mg-gluco-}$ nate, $50 \mathrm{mM}$ Tris, and $80 \mathrm{mM}$ Hepes ( $\mathrm{pH} 7.5)$. Uptake of ${ }^{36} \mathrm{Cl}^{-}(5$ $\mathrm{mM}$ ) was assayed in the presence of $80 \mu \mathrm{M}$ FCCP and $70 \mathrm{mM}$ sucrose, $0.2 \mathrm{mM}$ Ca-gluconate, $5 \mathrm{mM}$ Mg-gluconate, $50 \mathrm{mM}$ Tris, 80 $\mathrm{mM}$ Hepes (pH 7.5), and $100 \mathrm{mM} \mathrm{Na}^{+}(\bullet), 100 \mathrm{mM} \mathrm{K}^{+}(0), 50 \mathrm{mM}$ $\mathrm{Na}^{+}$and $50 \mathrm{mM} \mathrm{K}^{+}(\Delta)$, or $100 \mathrm{mM} \mathrm{TMA}^{+}(\Delta)$. Equilibrium $\mathrm{Cl}^{-}$ uptake values at $180 \mathrm{~min}$ were $9.5 \pm 0.6 \mathrm{nmol} \cdot \mathrm{mg}^{-1}$ protein for cLPM and $4.3 \pm 0.5 \mathrm{nmol} \cdot \mathrm{mg}^{-1}$ protein for blLPM vesicles $($ mean $\pm S D)$. Data represent the mean of three and six determinations in CLPM and bILPM vesicles, respectively.

$\mathrm{HCO}_{3}^{-}$plays an important role in the generation of BAIF in rat liver (9-11). Furthermore, studies with isolated hepatocytes in suspension have provided evidence for the existence of inorganic anion (e.g., $\mathrm{Cl}^{-}, \mathrm{HCO}_{3}^{-}$, and sulfate) transport systems on the surface membrane of normal liver cells (16). However, in that hepatocytes loose their structural and functional polarization during the course of their isolation, the physiologic distribution of these transport systems along the basolateral and canalicular surface domains are not known. Furthermore, studies with isolated hepatocytes do not distinguish between membrane transport processes and intracellular (e.g., cytosolic) metabolic events. In the present study, therefore, we used selectively isolated and highly purified CLPM and bILPM vesicles (23) to investigate the mechanisms and driving forces for transmembrane transport of $\mathrm{Cl}^{-}$across the two major surface domains of hepatocytes.

The results of these studies provide direct evidence for the existence of a carrier-mediated electroneutral $\mathrm{Cl}^{-}: \mathrm{HCO}_{3}^{-}\left(\mathrm{OH}^{-}\right)$ exchange in CLPM but not in blLPM vesicles (Figs. 2, 6, and 7). Because $\mathrm{HCO}_{3}^{-}$gradients resulted in greater initial rates of ${ }^{36} \mathrm{Cl}$ uptake than $\mathrm{OH}^{-}$gradients, the exchanger favors $\mathrm{HCO}_{3}^{-}$ over $\mathrm{OH}^{-}$anions at identical $\mathrm{pH}$ gradients. This preferential stimulation of $\mathrm{Cl}^{-}$uptake by $\mathrm{HCO}_{3}^{-}$could not be explained by an increase in buffering capacity because the concentration of Tris-Hepes was reduced by $50 \%$ when $\mathrm{HCO}_{3}^{-}$was added (Fig. 1), and stimulation by $\mathrm{HCO}_{3}^{-}$was observed at the earliest time points when buffering capacity should be adequate (Figs. 1 and 4). $\mathrm{Cl}^{-}: \mathrm{HCO}_{3}^{-}$exchange was most effectively inhibited by DIDS (70\%) and to a lesser extent also by equimolar amounts of SITS $(49 \%)$, probenecid (37\%), furosemide (33\%), and bumetanide (26\%; Table I, and Fig. 2). This pattern of inhibition is analogous to the effect of these compounds on $\mathrm{Cl}^{-}$transport in erythrocytes $(29,32)$, dog renal microvillus membrane vesicles (33), as well as rabbit ileal brush border membrane vesicles (17), and further suggests that at least a portion of transcanalicular $\mathrm{Cl}^{-}$movement is a carrier-mediated exchange with $\mathrm{HCO}_{3}^{-}$. Although a valinomycin-induced insidepositive $\mathrm{K}^{+}$diffusion potential also stimulated overall $\mathrm{Cl}^{-}$ uptake both in the presence (Fig. 6) and absence (Fig. 3) of outwardly directed $\mathrm{OH}^{-}$and $\mathrm{HCO}_{3}^{-}$gradients, the DIDSsensitive portion of the $\mathrm{pH}$ and $\mathrm{HCO}_{3}^{-}$gradient-stimulated $\mathrm{Cl}^{-}$ uptake was not affected by the artificially imposed transmembrane potential changes (Fig. 6), suggesting an electroneutral $\mathrm{Cl}^{-}: \mathrm{HCO}_{3}^{-}$exchange in cLPM. Altogether, this data indicates that in addition to a voltage-insensitive $\mathrm{Cl}^{-}: \mathrm{HCO}_{3}^{-}$exchange pathway, a physiologic conductive leak pathway for $\mathrm{Cl}^{-}$may exist in canalicular rat liver plasma membranes as well.

In contrast to the recently reported anion exchange mechanisms in rat renal basolateral (19) and dog renal microvillus $(20,21)$ membrane vesicles, the rat liver canalicular $\mathrm{Cl}^{-}$: $\mathrm{HCO}_{3}^{-}$exchange pathway, described in the present study, is not shared by other anions such as sulfate, $p$-aminohippurate, lactate, or acetate (no cis-inhibition of pH- and $\mathrm{HCO}_{3}^{-}$-stimulated $\mathrm{Cl}^{-}$uptake, Table II). Furthermore, we found no effect of $\mathrm{pH}$ and $\mathrm{HCO}_{3}^{-}$gradients on transcanalicular transport of taurocholate (8) nor was the $\mathrm{pH}$ and $\mathrm{HCO}_{3}^{-}$gradient-driven $\mathrm{Cl}^{-}$uptake affected to any degree by the addition of $100 \mu \mathrm{m}$ of taurocholate to the reaction mixture (data not shown). In contrast, nitrate may also be able to exchange with $\mathrm{HCO}_{3}^{-}$ (Table II). Thus, there appears to be a certain selectivity of the canalicular rat liver $\mathrm{Cl}^{-}: \mathrm{HCO}_{3}^{-}$exchange for inorganic anions rather than organic anions, as recently observed in rabbit brush border membranes (17). This interpretation is further substantiated by the greater inhibition of $\mathrm{pH}$ and $\mathrm{HCO}_{3}^{-}$gradient-stimulated $\mathrm{Cl}^{-}$uptake by DIDS and SITS as compared with probenecid (Table I). The latter represents the standard inhibitor of organic anion transport in the kidney (26) and has been shown to preferentially inhibit $\mathrm{pH}$ gradient stimulated urate and $p$-aminohippurate transport in dog renal microvillus vesicles (33). Future studies will be required to determine whether similar or different (albeit closely related) membrane components are responsible for the transcanalicular transfer of chloride, bicarbonate, and organic anions.

By utilizing highly purified and selectively isolated bILPM and CLPM vesicles, the present study resolves two major current controversies with respect to the hepatocellular transport of $\mathrm{Cl}^{-}$. First, the selective localization of the identified $\mathrm{Cl}^{-}$: $\mathrm{HCO}_{3}^{-}$exchange to the canalicular pole of hepatocytes (Fig. 7) explains why evidence for such an exchange mechanism has been found up to now only in isolated hepatocytes in suspension, where the canalicular surface is directly exposed to the surrounding medium (16). In contrast, $\mathrm{Cl}^{-}: \mathrm{HCO}_{3}^{-}$exchange was not found in the isolated perfused rat liver, probably because the canalicular membrane does not have direct contact with the perfusate in this experimental model (34). Secondly, we find no evidence for the existence of a $\mathrm{Na}^{+}: \mathrm{Cl}^{-}$co-transport system, either in blLPM or in CLPM vesicles (Fig. 8). In accordance with some (31) but not all (9) studies in the isolated perfused liver and cultured hepatocytes, these findings indicate the absence of a sodium coupled secondary active transport process for transhepatocyte excretion of $\mathrm{Cl}^{-}$. Thus, our data support the concept of a passive distribution of $\mathrm{Cl}^{-}$ across the various domains of the hepatocellular plasma membrane according to the physiologic electrochemical membrane potential $(4,5,35)$.

Fig. 9 integrates the identified canalicular $\mathrm{Cl}^{-}: \mathrm{HCO}_{3}^{-}$exchange as well as the $\mathrm{Cl}^{-}$conductive leak pathway into a new model for the formation of BAIF. According to this concept the intracellular negativity, that is maintained by the basolateral 
$\mathrm{Na}^{+} \mathrm{K}^{+}$-ATPase activity, leads to a passive (electrodiffusional) concentration of $\mathrm{Cl}^{-}$within the bile canalicular lumen compared with the cell interior. The resulting transcanalicular out to in $\mathrm{Cl}^{-}$concentration gradient can then drive electroneutral exchange for intracellular $\mathrm{HCO}_{3}^{-}$, the constant availability of which is guaranteed by metabolic formation of $\mathrm{CO}_{2}$ and the coordinated actions of cytosolic carbonic anhydrase (36) and basolateral $\mathrm{Na}^{+}: \mathrm{H}^{+}$exchange $(10,37,37 \mathrm{a})$. The latter pump will also maintain intracellular $\mathrm{HCO}_{3}^{-}$above its electrochemical equilibrium, thereby providing an additional driving force for the $\mathrm{Cl}^{-}: \mathrm{HCO}_{3}^{-}$exchanger. Because the canalicular $\mathrm{Cl}^{-}$concentration remains constant as long as the physiologic intracellular negative potential is maintained, these processes result in a net accumulation of $\mathrm{HCO}_{3}^{-}$within the bile canalicular lumen. Theoretically, this chloride driven out to in $\mathrm{HCO}_{3}^{-}$gradient could now energize the canalicular excretion of certain organic anions via a second anion exchange process. Although the existence of such a canalicular $\mathrm{HCO}_{3}^{-}$: organic anion exchange mechanism is hypothetical at present, $\mathrm{pH}$ - and $\mathrm{HCO}_{3}^{-}$-dependent organic anion exchangers with very broad substrate specificities have been recently identified in $\operatorname{dog}(20,33)$ and rat (21) renal microvillus as well as rat renal basolateral membrane vesicles $(18,19)$. Inasmuch as kidney and liver excrete similar organic anions (38-41), it appears reasonable to propose that the two organs may also possess similar membrane transport processes.

The model presented in Fig. 9 satisfies several observations concerning the subcellular mechanisms involved in overall hepatic bile formation. First, the findings that the canalicular excretion of taurocholate $(7,8)$ as well as chloride (this study, Fig. 3) are both driven by the intracellular negative potential strengthen the concept that the activity of basolateral $\mathrm{Na}^{+} \mathrm{K}^{+}$. ATPase and the outward conductive diffusion of $\mathrm{K}^{+}$provide a major "driving force" for both components of canalicular bile flow, e.g., BADF and BAIF $(1,5,42)$. Second, the absence of $\mathrm{Na}^{+}: \mathrm{Cl}^{-}$co-transport in blLPM vesicles (Fig. 8) in conjunction with the presence of a conductive leak pathway for $\mathrm{Cl}^{-}$ in CLPM (Fig. 3) suggest that the passive electrodiffusion of intracellular $\mathrm{Cl}^{-}$into the canalicular lumen plays an important role in the generation of BAIF $(5,9)$. Indeed, inhibition of $\mathrm{Na}^{+} \mathrm{K}^{+}$-ATPase (membrane depolarization) results in intracellular sequestration of $\mathrm{Cl}^{-}, \mathrm{Na}^{+}$, and water (43); whereas, hyperpolarization of the cell membrane is associated with an increased hepatocellular efflux of $\mathrm{Cl}^{-}$into bile and a transient

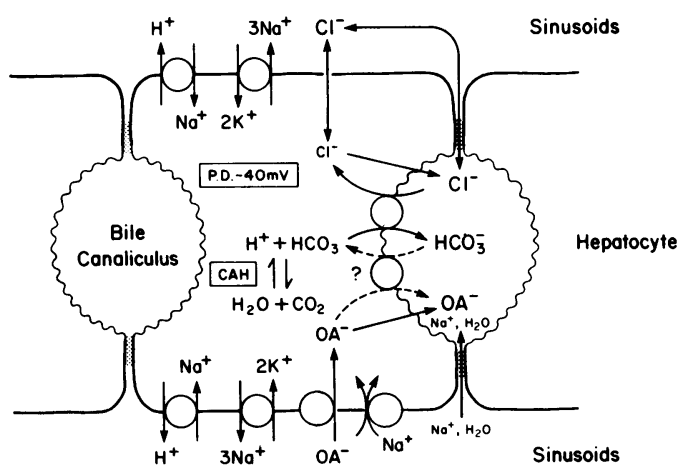

Figure 9. Model for a role of the identified electroneutral canalicular $\mathrm{Cl}^{-}: \mathrm{HCO}_{3}^{-}$exchange in bile acid-independent bile formation in rat liver. For discussion of the model see text. P.D., potential difference with respect to the extracellular space; $\mathrm{CAH}$, cytosolic carbonic anhydrase; $\mathrm{OA}^{-}$, organic anions (e.g., taurocholate; 7,8 ). rise in bile flow (44). Third, an electroneutral cLPM Cl${ }^{-}$: $\mathrm{HCO}_{3}^{-}$exchanger (Figs. 1, 2, and 6) can also explain why omission of perfusate $\mathrm{HCO}_{3}^{-}$from rat liver perfusate results in a decrease of BAIF in the isolated perfused rat liver (9-11). In one study an additive decrease in BAIF was also observed after sequential omission of $\mathrm{Cl}^{-}$and $\mathrm{HCO}_{3}^{-}$from the perfusate (9), findings consistent with a high intraluminal $\mathrm{Cl}^{-}$concentration stimulating the canalicular excretion of intracellular $\mathrm{HCO}_{3}^{-}$(Fig. 9).

Our data does not exclude the possibility of a separate conductive leak pathway for $\mathrm{HCO}_{3}^{-}$in $\mathrm{CLPM}$, which also could generate net $\mathrm{HCO}_{3}^{-}$excretion, particularly if a basolateral $\mathrm{Na}^{+}$: $\mathrm{H}^{+}$exchanger maintains intracellular $\mathrm{HCO}_{3}^{-}$above its electrochemical equilibrium. Functional coupling between basolateral $\mathrm{Na}^{+}: \mathrm{H}^{+}$exchange and canalicular $\mathrm{Cl}^{-}: \mathrm{HCO}_{3}^{-}$exchange may also exist in the liver cell, and $\mathrm{Na}^{+}: \mathrm{H}^{+}$exchange could be the major driving force rather than the $\mathrm{CLPM} \mathrm{Cl}{ }^{-}$gradient. The resistance of biliary $\mathrm{HCO}_{3}^{-}$secretion to replacement of $\mathrm{Na}^{+}$by $\mathrm{Li}^{+}$in the perfused rat liver (9-11) could also be explained by such functional coupling, since $\mathrm{Li}^{+}$can effectively replace $\mathrm{Na}^{+}$ for exchange with $\mathrm{H}^{+}$in the liver as well as the kidney, and intestine $(13,28,37 \mathrm{a})$. Finally the identification of a canalicular $\mathrm{Cl}^{-}: \mathrm{HCO}_{3}^{-}$exchanger provides an additional mechanism to duct $\mathrm{HCO}_{3}^{-}$excretion for enriching bile bicarbonate content in many animal species $(10,45)$.

In summary, the present study provides direct evidence for the existence of an electroneutral $\mathrm{Cl}^{-}: \mathrm{HCO}_{3}^{-}$exchanger as well as a conductive leak pathway for $\mathrm{Cl}^{-}$in canalicular plasma membrane vesicles of rat liver. Although these findings have been discussed with respect to their possible physiologic significance in bile acid-independent bile formation, it is realized that $\mathrm{Cl}^{-}$and $\mathrm{HCO}_{3}^{-}$transport processes might also be involved in the control of cell volume and the regulation of intracellular pH $(43,46,47)$. Thus, it is possible that in the intact liver a dynamic relationship exists between the canalicular excretion of $\mathrm{Cl}^{-}$and $\mathrm{HCO}_{3}^{-}$and $\mathrm{Na}^{+} / \mathrm{H}^{+}$exchange and the regulation of cell volume and intracellular $\mathrm{pH}$. Elucidation of these functional interdependencies will require studies in intact cells including micropuncture of bile canaliculi in isolated couplets of hepatocytes (48).

\section{Acknowledgments}

We thank C. Barrett for excellent technical assistance, P. S. Aronson for helpful discussions, and S. D. Wilder and A. Reuben for efficient typing of the manuscript.

This work was supported by U. S. Public Health Service grants AM-25636, AM-31493, and AM-31969.

\section{References}

1. Boyer, J. L. 1980. New concepts of mechanisms of hepatocyte bile formation. Physiol. Rev. 60:303-326.

2. Blitzer, B. L., and J. L. Boyer. 1982. Cellular mechanisms of bile formation. Gastroenterology. 82:346-357.

3. Reichen, J., and G. Paumgartner. 1980. Excretory function of the liver. In Liver and Biliary Tract Physiology I. Int. Rev. Physiol. 21:103-150.

4. Scharschmidt, B. F., and R. W. Van Dyke. 1983. Mechanisms of hepatic electrolyte transport. Gastroenterology. 85:1199-1214.

5. Graf, J. 1983. Canalicular bile salt-independent bile formation: concepts and clues from electrolyte transport in rat liver. Am. J. Physiol. 244:G233-G246.

6. Erlinger, S. 1981. Hepatocyte bile secretion: current views and controversies. Hepatology. 1:352-359. 
7. Inoue, M., R. Kinne, T. Tran, and J. M. Arias. 1984. Taurocholate transport by rat liver canalicular membrane vesicles. Evidence for the presence of an $\mathrm{Na}^{+}$-independent transport system. J. Clin. Invest. 73: 659-663.

8. Meier, P. J., A. St. Meier-Abt, C. Barrett, and J. L. Boyer. 1984 Mechanisms of taurocholate transport in canalicular and basolatera rat liver plasma membrane vesicles. Evidence for an electrogenic canalicular organic anion carrier. J. Biol. Chem. 259:10614-10622.

9. Anwer, M. S., and D. Hegner. 1983. Role of inorganic electrolytes in bile acid-independent canalicular bile formation. Am. J. Physiol. 244:G116-G124.

10. Hardison, W. G. M., and G. A. Wood. 1978. Importance of bicarbonate in bile salt independent fraction of bile flow. Am. J. Physiol. 235:E158-E164.

11. Van Dyke, R. W., J. E. Stephens, and B. F. Scharschmidt 1982. Effect of ion substitution on bile acid-dependent and bile acidindependent bile formation by the isolated perfused rat liver. J. Clin. Invest. 70:505-517.

12. Klos, C., G. Paumgartner, and J. Reichen. 1979. Cation-anion gap and choleretic properties of rat bile. Am. J. Physiol. 236:E434E441.

13. Aronson, P. S. 1983. Mechanisms of active $\mathrm{H}^{+}$secretion in the proximal tubule. Am. J. Physiol. 245:F647-F659.

14. Murer, H., and G. Burckhardt. 1983. Membrane transport of anions across epithelia of mammalian small intestine and kidney proximal tubule. Rev. Physiol. Biochem. Pharmacol. 96:1-51.

15. Murer, H., G. Ahearn, J. Biber, G. Cassano, P. Gmaj, and B. Steiger. 1983. Co- and counter-transport mechanisms in brush border membranes and basal-lateral membranes of intestine and kidneys. $J$. Exp. Biol. 106:163-180.

16. von Dippe, P., and D. Levy. 1982. Analysis of the transport system for inorganic anions in normal and transformed hepatocytes. J. Biol. Chem. 257:4381-4385.

17. Knickelbein, R. G., P. S. Aronson, J. Seifter, and J. W. Dobbins. 1985. $\mathrm{Na}$ and $\mathrm{Cl}$ transport across rabbit ileal brush border. II. Evidence for $\mathrm{Cl}: \mathrm{HCO}_{3}$ exchange and mechanism of coupling. Am. J. Physiol. In press.

18. Pritschard, J. B., and J. L. Renfro. 1982. Renal sulfate transport at the basolateral membrane is mediated by anion exchange. Proc. Natl. Acad. Sci. USA. 80:2603-2607.

19. Loew, I., T. Friederich, and G. Burckhardt. 1984. Properties of an anion exchanger in rat renal basolateral membrane vesicles. Am. J. Physiol. 246:F334-F342.

20. Guggino, S. E., G. J. Martin, and P. S. Aronson. 1983. Specificity and modes of the anion exchanger in dog renal microvillus membranes. Am. J. Physiol. 244:F612-F621.

21. Kahn, A. M., S. Branham, and E. J. Weinman. 1983. Mechanism of urate and $p$-aminohippurate transport in rat renal microvillus membrane vesicles. Am. J. Physiol. 245:F151-F158.

22. Meier, P. J., R. Knickelbein, R. H. Moseley, and J. L. Boyer. 1984. Evidence for $\mathrm{Cl}: \mathrm{HCO}_{3}$ (and $\mathrm{OH}$ ) anion exchange in canalicular rat liver plasma membrane vesicles. Gastroenterology. 86:1331. (Abstr.)

23. Meier, P. J., E. S. Sztul, A. Reuben, and J. L. Boyer. 1984. Structural and functional polarity of canalicular and basolateral plasma membrane vesicles isolated in high yield from rat liver. J. Cell Biol. 98:991-1000.

24. Seifter, J. L., and P. S. Aronson. 1984. $\mathrm{Cl}^{-}$transport via anion exchange in Necturus renal microvillus membranes. Am. J. Physiol. 247:F888-F895

25. Cabantchik, Z. J., P. A. Knauf, and A. Rothstein. 1978. The anion transport system of the red blood cell. The role of membrane protein evaluated by the use of "probes." Biochim. Biophys. Acta. 515: 239-302.

26. Moller, J. V., and J. Sheikh. 1983. Renal organic anion transport system: pharmacological, physiological, and biochemical aspects. Pharmacol. Rev. 34:315-358.

27. Kinsella, J. L., and P. S. Aronson. 1981. Amiloride inhibition of the $\mathrm{Na}^{+}-\mathrm{H}^{+}$exchanger in renal microvillus membrane vesicles. $A m$. J. Physiol. 241:F374-F379.

28. Knickelbein, R., P. S. Aronson, W. Atherton, and J. W. Dobbins. 1983. Sodium and chloride transport across rabbit ileal brush border. I. Evidence for Na-H exchange. Am. J. Physiol. 245:G504G510.

29. Brazy, P. C., and R. B. Gunn. 1976. Furosemide inhibition of chloride transport in human red blood cells. J. Gen. Physiol. 68:583599.

30. Segel, J. H. 1975. Enzyme Kinetics. Behavior and Analysis of Rapid Equilibrium and Steady-State Enzyme Systems. John Wiley and Sons, New York. 100-159.

31. Scharschmidt, B. F., R. W. van Dyke, and J. E. Stephens. 1982. Chloride transport by intact rat liver and cultured rat hepatocytes. Am. J. Physiol. 242:G628-G633.

32. Motais, R., and J. L. Cousin. 1976. The inhibitor effect of probenecid and structural analogues on organic anions and chloride permeabilities in ox erythrocytes. Biochim. Biophys. Acta. 419:309313.

33. Kahn, A. M., and P. S. Aronson. 1983. Urate transport via anion exchange in dog renal microvillus membrane vesicles. Am. $J$. Physiol. 244:F56-F63.

34. Bracht, A., A. Kelmer-Bracht, A. J. Schwab, and R. Scholz. 1981. Transport of inorganic anions in perfused rat liver. Eur. $J$ Biochem. 114:471-479.

35. Claret, M., and J. L. Mazet. 1972. Ionic fluxes and permeabilities of cell membranes in rat liver. J. Physiol. (Lond.). 223:279-295.

36. Maren, T. H., and G. Sanyal. 1983. The activity of sulfonamides and anions against the carbonic anhydrases of animals, plants, and bacteria. Annu. Rev. Pharmacol. Toxicol. 23:439-459.

37. Arias, I. M., and M. Forgac. 1984. The sinusoidal domain of the plasma membrane of rat hepatocytes contains an amiloridesensitive $\mathrm{Na}^{+} / \mathrm{H}^{+}$antiport. J. Biol. Chem. 259:5406-5408.

37a. Moseley, R. H., P. J. Meier, R. Knickelbein, P. S. Aronson, and J. L. Boyer. 1984. Evidence for $\mathrm{Na}^{+}-\mathrm{H}^{+}$exchange in rat liver basolateral but not canalicular membrane vesicles. Hepatology. 4:1046. (Abstr.)

38. Sperber, I. 1959. Secretion of organic anions in the formation of urine and bile. Pharmacol. Rev. 11:109-134.

39. Woo, F. H., and S. K. Hong. 1963. Renal and hepatic excretions of phenol red and bromosulphalein in the dog. Am. J. Physiol. 204:776-780.

40. Despopoulos, A. 1966. Congruence of excretory functions in liver and kidney: hippurates. Am. J. Physiol. 210:760-764.

41. Despopoulos, A. 1971. Congruence of renal and hepatic excretory functions: sulfonic acid dyes. Am. J. Physiol. 220:17551758.

42. Erlinger, S. 1982. Does $\mathrm{Na}^{+}-\mathrm{K}^{+}-\mathrm{ATPase}$ have any role in bile secretion? Am. J. Physiol. 243:G243-G247.

43. van Rossum, G. D. V., and M. A. Russo. 1984. Requirement of $\mathrm{Cl}^{-}$and $\mathrm{Na}^{+}$for the ouabain resistant control of cell volume in slices of rat liver. J. Membr. Biol. 77:63-76.

44. Graf, J. 1976. Sodium pumping and bile secretion. In The Liver: Quantitative Aspects of Structure and Function. R. Preisig, J. Bircher, and G. Paumgartner, editors. Editio Cantor, Aulendorf, Federal Republic of Germany. 370-385.

45. Erlinger, S. 1982. Secretion of bile. In Diseases of the Liver. L. Schiff and E. Schiff, editors. Philadelphia, PA. J. B. Lippincott Co. 93-118.

46. Roos, A., and W. F. Boron. 1981. Intracellular pH. Physiol. Rev. 61:296-434.

47. Ives, H. E., and F. C. Rector. 1984. Proton transport and cell function. J. Clin. Invest. 73:285-290.

48. Graf, J., A. Gautam, and J. L. Boyer. 1984. Isolated rat hepatocyte couplets: a primary secretory unit for electrophysiologic studies of bile secretory function. Proc. Natl. Acad. Sci. USA. 81:65166520. 